\title{
A INTERFERÊNCIA DOS PARQUES URBANOS NA SAÚDE PÚBLICA: UMA ANÁLISE DO MUNICÍ- PIO DE NOVA IGUAÇU - RJ
}

Cristiane Luiz de Paula da Costa Graduanda em Arquietetura e Urbanismo pelo Centro Universitário Augusto Motta (UNISUAM), RJ, Brasil cris200484@ymail.com

Geovana Rios do Carmo Soares Graduanda em Arquitetura e Urbanismo pelo Centro Universitário Augusto Motta (UNISUAM), RJ, Brasil geehsoaress96@gmail.com

Jose Roberto Moreira Ribeiro Gonçalves Mestre em Engenharia Agrícola e Ambiental pela UFRRJ, RJ, Brasil Professor do Centro Universitário Augusto Motta (UNISUAM), RJ, Brasil joserobertoverde@gmail.com

\section{RESUMO}

O presente artigo teve como finalidade apresentar como os parques urbanos atrelados a vegetação são elementos essênciais para a cidade e para a saúde urbana, pois melhoram a qualidade do ar na atmosfera, a poluição sonora, e promove equilíbrio climático. Além de uma área de lazer e atividades físicas para que as pessoas usufruem do espaço. Também oferecem uma melhor qualidade de vida junto a natureza, como a melhoria do psíquico do ser humano com seu efeito repousante. O verde das árvores representam um ponto positivo para a vitalidade urbana assim como a beleza do parque representa um ponto positivo para o vigor do ser humano, e ganhamos com isso uma cidade sustentável e muito mais humanitária. O outro objetivo do estudo foi apresentar as diferenças entre cidade com alto e baixo poder aquisitivo, como as pessoas vêem estas áreas em sua localidade, como podem interferir na qualidade de vida do indivíduo. Discutiremos a socialização e a implantaçãos desses espaços em cidades com habitantes de baixa renda. Pode-se considerar que as funções socioeconômica e ambientais devem sim andar juntas, complementando uma a outra, com atividades de educação e reeducação social, resgatando os valores pessoais, sociais, culturais e históricos tanto da cidade como do ser humano. É importante um equipamento urbano que modifique a reprodução do espaço e a valorização do lugar, por isso não podendo ser desconsiderado e irrelevante a nenhum tipo de cidade, sendo ela de alto padrão social ou não.

Palavras-chave: Parque Urbano. Saúde pública. Saúde física. 


\begin{abstract}
The purpose of this article was to present how urban parks have become an essential element for the city and for urban health, since it improves air quality in the atmosphere, noise pollution, and the promotion of climate balance. In addition to an area of leisure and physical activities for people as they enjoy the space. You can also improve the quality of your life as a psychic. The green of the book represents a positive point for urban vitality and represents a sustainable and much more humane city. The other objective of the study was to present as the differences between the city with high and low purchasing power, how people see the areas in their locality, how they can interfere in the quality of life of the individual. We will discuss socialization and deployment of these spaces in cities with low-income people. Socioeconomic and political functions must be carried out together, complementing one another, with activities of education and social re-education, rescuing the personal, social, cultural and historical values of the city as human beings. It is important an urban equipment that modifies the reproduction of the space and the valuation of the place, so it is not to be disregarded and irrelevant as a type of city, being of high social standard or not.
\end{abstract}

Keywords: Urban Park. Public health. Physical health.

\title{
1 INTRODUÇÃO
}

As praças e parques públicos, com áreas para brincar, sentar, se exercitar, passear cumprem papel primordial na cidade. Os espaços livres públicos, para o lazer e a fruição na cidade contemporânea são considerados vitais para a vida cotidiana. Neles usuários adultos e crianças desenvolvem atividades relacionadas ao lazer, exercitando o corpo, mente, ou em ações para a diversão e a contemplação, benéficas para a qualidade de vida urbana, distintas das horas de trabalho dirigidas ou planejadas. Pisos, mobiliário urbano de recreação e lazer, infraestrutura para o uso, além do paisagismo são importantes para qualificar, e propiciar a apropriação do local (Vieira et al., 2016).

São mais conhecidos como parques, jardins ou praças, áreas que predominam o espaço com vegetação plantada, cuja principal função é estimular a vida comunitária, são locais verdes normalmente com $100 \mathrm{~m}^{2}$ ou 10 ha, contudo não se pode padronizar sem conhecer o entorno. Muitas cidades colocam todo o espaço não construído como área verde, aumentam seus índices fazendo isso, e para calcular o índice de área verde, devem ser consideradas somente arborizações públicas, ligado ao uso direto da popu- 
lação que reside nesse espaço (Oliveira et al., 2006).

As áreas públicas de lazer, bem como a busca pela melhoria da qualidade de vida dos munícipios como resultado desses espaços, são de extrema importância, mas ainda existem barreiras apesar do lazer está presente na Constituição de 1988 como direito do cidadão, existem muitos empecilhos no que diz respeito à prática do lazer nos espaços públicos oferecidos (Santana et.al, 2014).

De acordo com (Freitas et al., 2015) os espaços livres públicos são elementos organizadores na malha urbana, com tamanho equivalentes de uma quadra, expressivas coberturas vegetais, mobiliário lúdico, canteiros e bancos.

Segundo (Oliveira et al., 2013) a cidade precisa de organização e planejamento devido ao crescimento desordenado, e para podermos perceber a vegetação e os itens necessário ao espaço urbano. Levando em conta a saúde urbana os parques sem arborização não desempenham sua correta função em relação ao conforto térmico, como exemplo a Praça Seca, Mauá e a Tiradentes no Rio de Janeiro, que oferecem um grande desconforto térmico devido a falta de elementos vegetais, influênciando diretamente na qualidade ambiental e climática.

A vida com visitas em áreas bem planejadas despertam o interesse pelo uso, diminui o sedentarismo e o estresse urbano, porque o urbanismo contemporâneo gera essa necessidade de fugir dos ruídos através de áreas arbóreas. Vale ressaltar que 5 minutos de caminhada já são suficiente para melhorar a saúde mental, e a salubridade. Academias ao ar livre são de fundamental importância para isso também, mas as pessoas precisam se sentir atraídas por toda a área aberta (Macedo et al., 2009).

A praça é um ponto de refúgio entre o natural e o construído, mais associado à recreação através de caminhadas, socialização, jogos e relaxamentos. Arquitetos e Urbanistas devem planejar também locais de aprendizados para as crianças ao ar livre. O desenvolvimento da tecnologia, diminuição dos espaços livres pela aglomeração urbana, levaram os indivíduos a terem estilo de vida inativo (Macedo et al., 2009).

Os parques são frequentados por diversos tipos de pessoas e motivos diferentes, principalmente, pela acessibilidade, beleza e segurança, junto com a limpeza do mesmo. Os idosos e adultos usam os parques para evitar e preveni agravos de doenças pelo prazer, os jovens somente pelo prazer. Pode-se observar que esses tipos de espaços também reduzem o comportamento anti-social, tornando-se fonte de lazer, indicando a total importância do indivíduo com o meio ambiente, e seus efeitos benéficos, sendo 
o grande promotor de sáude mental (Perone et al., 2016).

Alertam (Gonçalves et al., 2013) que o uso de mesas de tabuleiro estimulam atividade intelectual, não restringindo somente à fisica.

O espaço público é o local de todos, atende a várias funções, importante local de contato com a natureza, com outras pessoas na troca de valores e socialização, como encontrar colegas, brincar (atividade ao qual a criança exercita sua sensibilidade, sua coordenação motora, sua mente e criatividade) (Vieira et al., 2016).

\section{REVITALIZAÇÃO DA FAZENDA SÃO BERNARDINO E PARQUES PÚBLICOS EM NOVA IGUAÇU}

Alguns locais do Rio de Janeiro são carentes de parques públicos, como em Nova Iguaçu, que conta apenas com dois, o Parque Natural (Figura 1) e o Municipal de Nova Iguaçu (Figura 2), uma pena para saúde urbana das pessoas, mas o local possui uma proposta de um novo parque através da Fazenda São Bernadinho (Figura 3) que foi destruída por um incêndio, na década de 1980, e ficou abandonada até os dias de hoje. A fazenda histórica fica entre o bairro de Vila de Cava e Tinguá, às margens da RJ-111, também chamada de Rodovia Federal, em Nova Iguaçu (O melhor da baixada, 2017).

Ela será revitalizada e restaurada para receber um parque público. É uma fazenda muito antiga, que está no local sem utilidade, se deteriorando. Fundada em 1875, ela possui $16 \mathrm{mil} \mathrm{m}^{2}$ de área e foi dada à prefeitura da cidade com o objetivo de restauração do ambiente (O melhor da baixada, 2017).

A prefeitura enviou o projeto de restauração da fazenda para análise do Iphan (Instituto do Patrimônio Histórico e Artístico Nacional), e o local é tombado desde 1951. O projeto consiste em reestruturar toda a Fazenda São Bernardino, seguindo os conceitos arquitetônicos da época, em estilo neoclássico, incluindo a casa grande, principalmente sua fachada, a senzala, engenho e terreiro, para transformar o local em um espaço para diversas atividades culturais e artísticas (O melhor da baixada, 2017). 
Figura 1 - Parque Natural de Nova Iguaçu

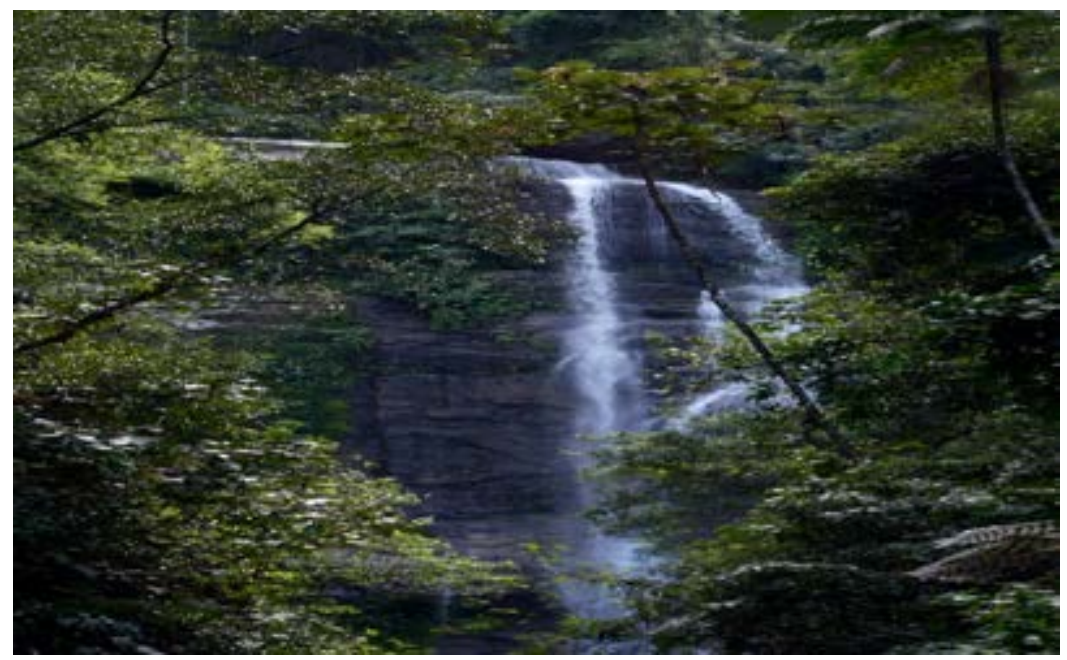

Fonte: (Prefeitura de Nova Iguaçu)

Figura 2 - Parque Municipal de Nova Iguaçu

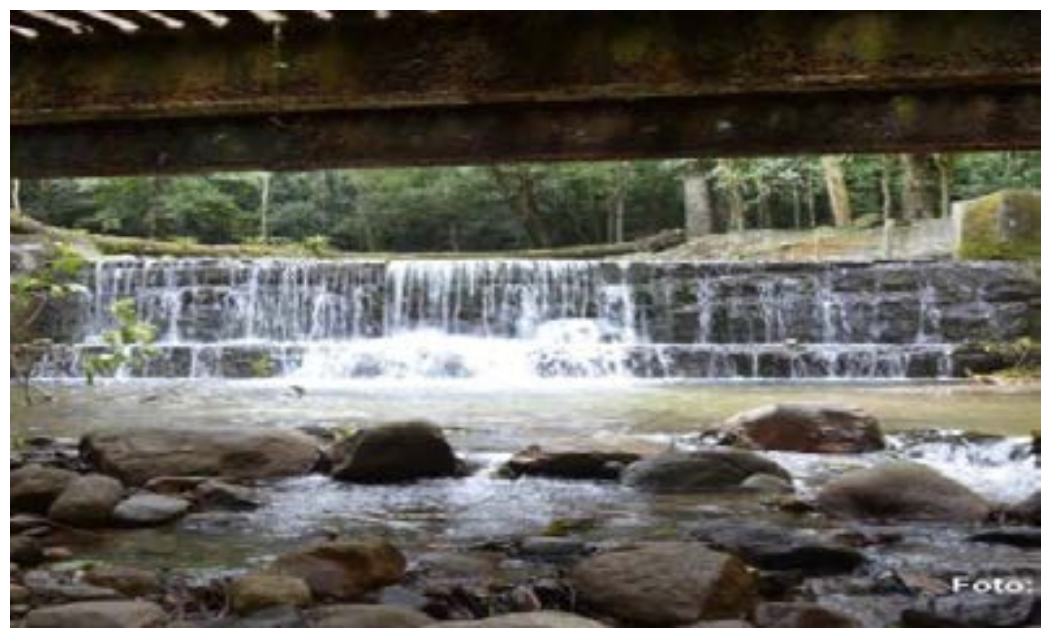

Fonte: (Prefeitura de Nova Iguaçu) 
Figura 3 - Fazenda São Bernadinho

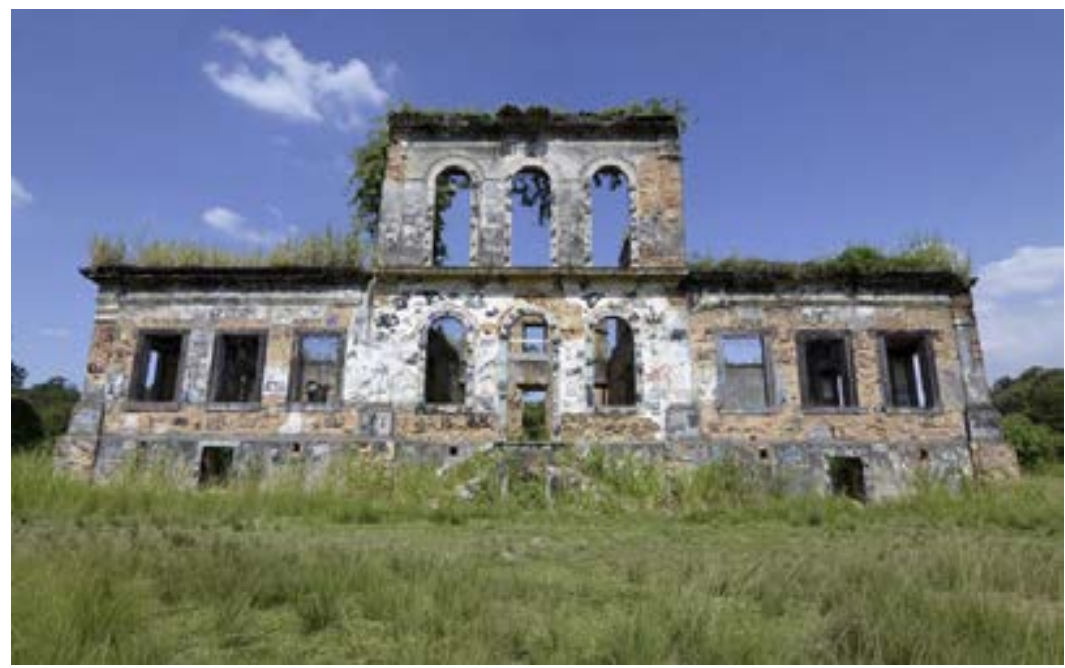

Fonte: (O melhor da baixada, 2017)

O local tem um apelo histórico muito grande. Tem um pouco da história da Cidade e do Brasil, pois possui a Estrada do Comércio, tinha um porto muito próximo, então a proposta é transformar em um local de encontro para reviver de alguma forma esses momentos (O melhor da baixada, 2017).

Antigamente, no local era encontrado cavalariças, garagem para carruagens, senzalas, habitações para escravos e engenhos de cana e mandioca. Lá também era produzido café, açúcar, aguardente e farinha de mandioca, além de extrair madeira e exportar carvão (O melhor da baixada, 2017).

Desde os primóridos a praça constitui referêncial urbano marcado pela convivência humana, um importante equipamento histórico-cultural, principalmente no Brasil. A imagem de uma praça se diferencia pela sua história, além da sua importância e seu uso significativo para população, principalmente de baixo poder aquisitivo que tem esses locais como área de lazer e de atividades física com os mobiliários urbanos adequados (Romani et al., 2012).

A ABNT (1986) - NBR 9283, considera mobiliário urbano como: "todos os objetos, elementos e pequenas construções integrantes da paisagem urbana, de natureza utilitária ou não, implantada mediante autorização do poder público em espaços públicos e privados". Segundo (ZIOBER, 2015) o conjunto de produtos denominados "Academia ao Ar Livre" tem variações em função de determinados públicos, como para a terceira 
idade (A.T.I); para jovens adultos (A.J.A); para cadeirantes (A.P.C) e para crianças (A.P.I), consideradas nesta pesquisa como equipamentos de mobiliário urbano.

Em São Paulo foi desenvolvido área do playground em algumas praças e parques da cidade, denominado Academia da Primeira Idade (A.P.I.), que tem como público usuário as crianças e seus responsáveis que utilizam este espaço (Vieira et al., 2016).

O maior conforto para população é resultado de mais árvores nas cidades, são elementos fundamentais na paisagem urbana, podendo minimizar o impacto ambiental causado pelos efeitos antrópicos decorrentes da expansão das cidades, atrelado ao processo de industrialização (Moreira et al., 2014).

A produção acadêmica vinculada com a comunidade é muito importante, lembrando sempre que os indivíduos não são apenas objeto de estudo, são interlocutores (Gonçalves et al., 2015).

\section{PARQUES PÚBLICOS NA CAPITAL DO RIO DE JANEIRO}

No Rio de Janeiro pode-se relacionar 14 parques públicos que servem como áreas de lazer que reúnem centenas de pessoas, entre eles, podemos citar o parque da Quinta da Boa Vista (Figura 4), Parque Laje (Figura 5), Catumba, Nacional Floresta da Tijuca (Figura 6 e 7), Parque Nacional, Natura de Marapendi, Passeio Público, Aterro do Flamengo, Pedra Bonita, Bosque da Barra, Chacrinha em Copacabana, Parque ecológico Chico Mendes, e Praça da República. Todos ofertam locais com área de lazer e atividades físicas e muita vegetação. A cidade oferece a seus usuários opções de lazer e entreterimento com algumas áreas verdes espalhadas pelo local, conseguindo atrair milhares de pessoas para seu território. São ofertados espaços para caminhadas, atividades físicas, pequiniques, atrações e shows, com estes recursos é possível diminuir o grande impacto climático de uma região quente, melhorando também o aspecto físico do local com uma vegetação enriquecida com diversas espécieis (Site: Opnião e notícia, 2015).

Ressaltam (Alencar et al., 2014) que a diversidade de espécies favorece o desempenho de distintas funções no meio urbano, tais como: beleza estética; retenção de partículas e elementos químicos dispersos na atmosfera, o que consequentemente melhora a qualidade do ar e, absorção do $\mathrm{CO}_{2}$ e liberação de $\mathrm{O}_{2}$, reduzindo assim a temperatura e proporcionando conforto térmico. 
Figura 4 - Quinta da Boa Vista

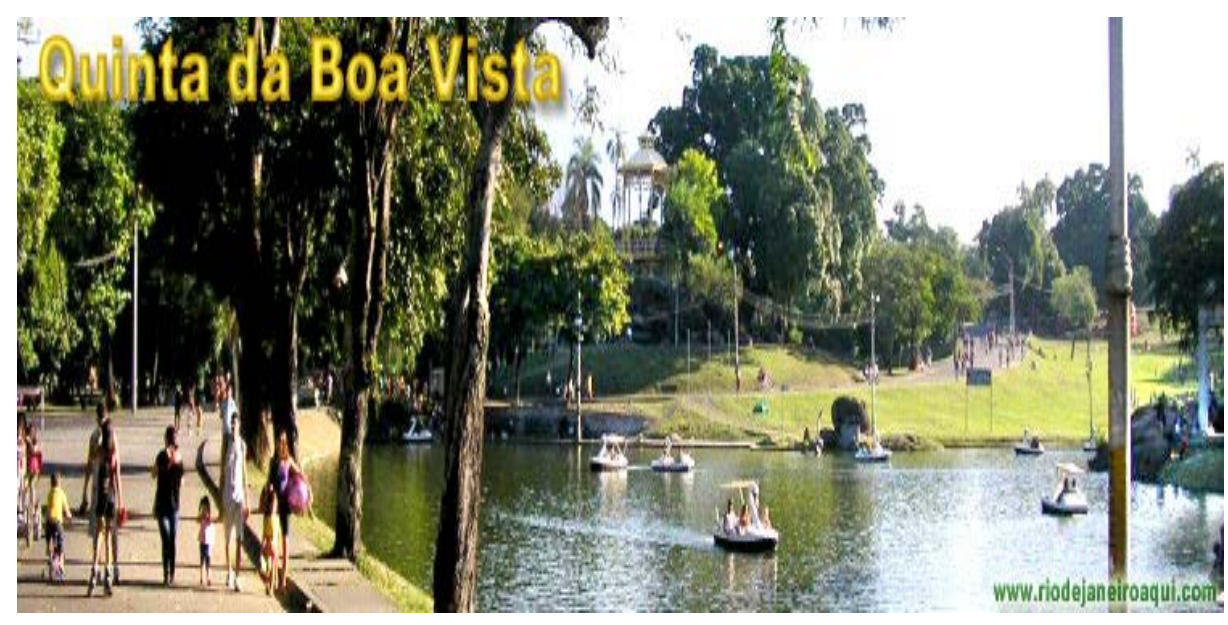

Fonte: (Rio de janeiro aqui)

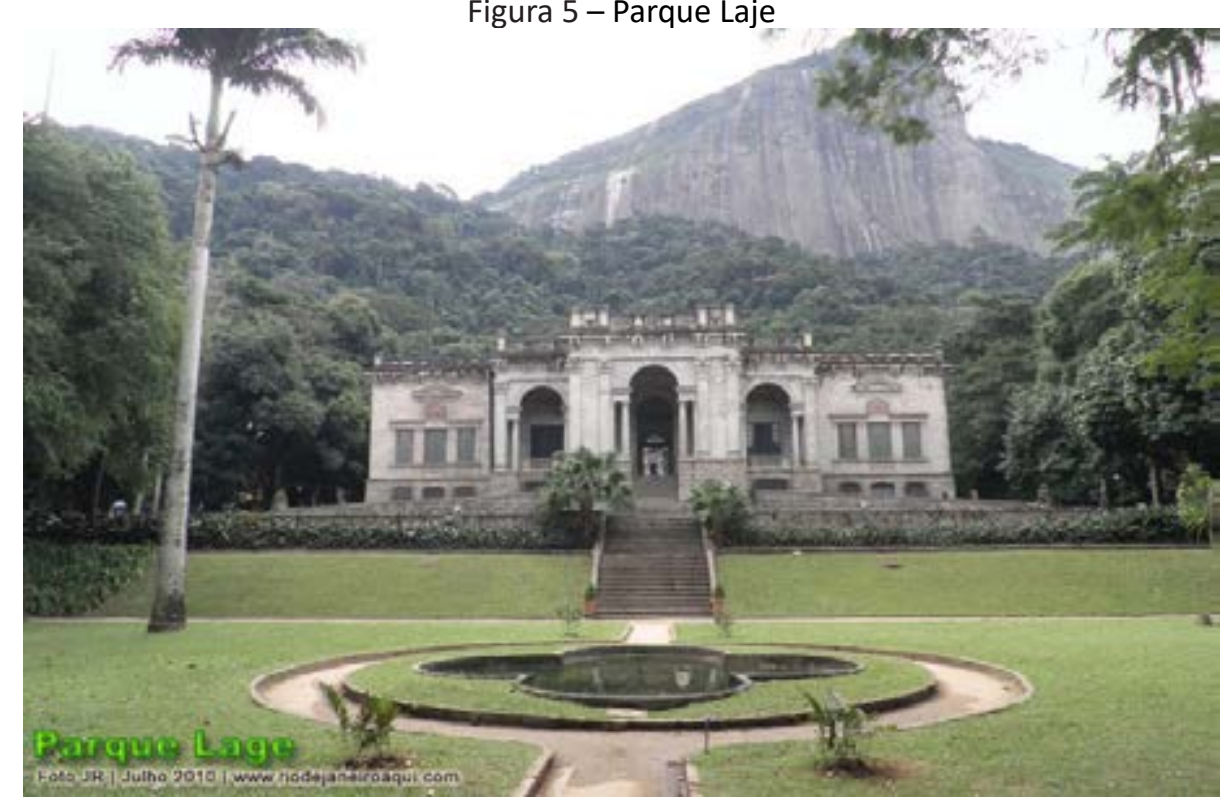

Fonte: (Rio de Janeiro aqui) 
Figura 6 - Floresta da Tijuca

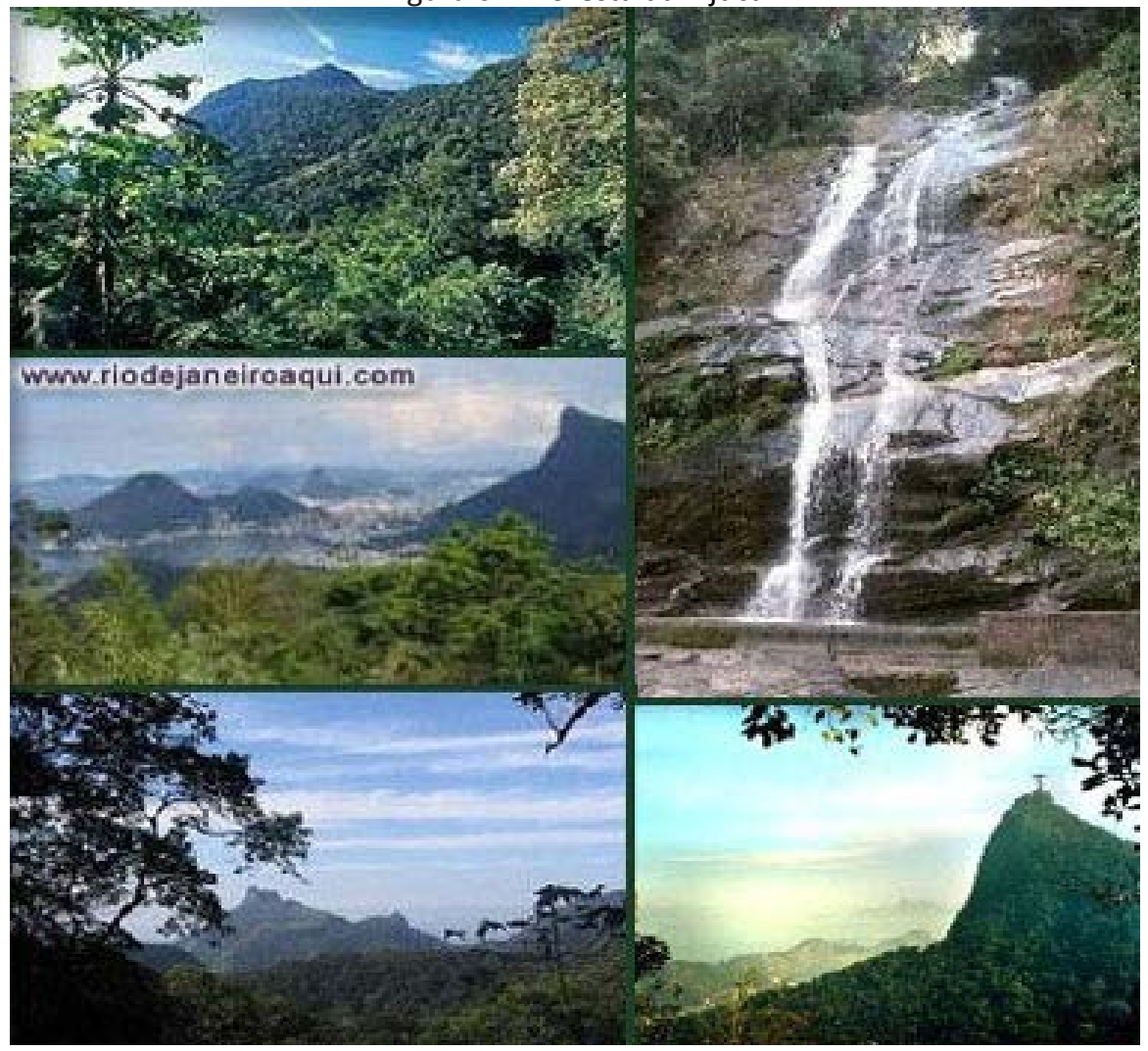

Fonte: (Rio de Janeiro aqui)

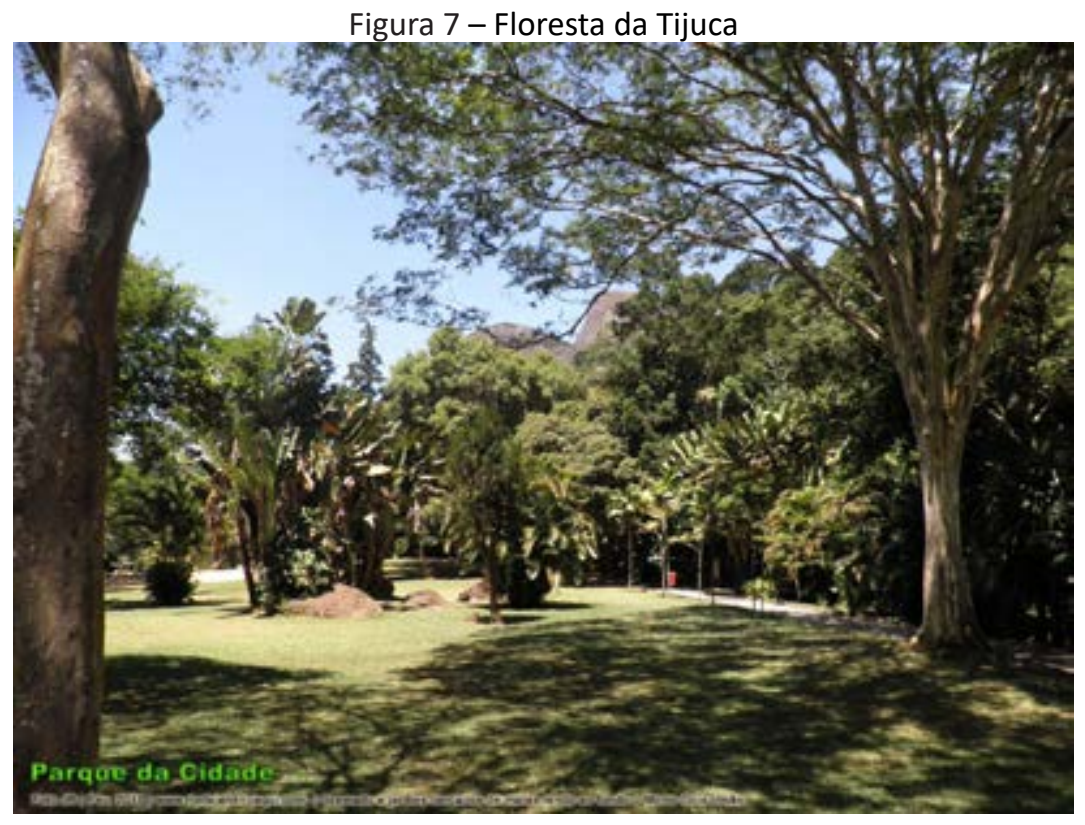

Fonte: (Rio de Janeiro aqui) 


\section{COMPARAÇÃO ENTRE OS PARQUES PÚBLICOS DA CAPITAL DO RIO DE JANEIRO E DE NOVA IGUAÇU}

Na capital, atrelam os parques ao convívio social, atraindo a população de uma forma geral com sua beleza, limpeza e segurança, assim milhares de olhares curiosos despertam a vontade de ir conhecer o local e após este primeiro contato normalmente aderem o espaço como seu, se sentem atraídos pelo local, e associam seu bem com aquele espaço, criam motivação para fazer caminhada em um lugar tão belo e com uma atmosfera diferenciada, a calmaria e tranquilidade que o ambiente exerce tambem é um dos motivos das atrações. Tendo em vista uma cidade agitada e movimentada, foram destacados acima 4 parques diferentes e que exercem a mesma função de atrair e acolher a sociedade para um momento de lazer, causando também um estímulo ao execício físico, e conivívio social idependentemente da classe destes indivíduos, aumentando o equilíbrio psíquico, melhorando a qualidade de vida e sáude pública (Catraca livre-notícias, 2018).

Em Nova Iguaçu pode-se observar dois parques com uma mesma estrutura, apesar da beleza do local, existe a resistência da utilização das áreas pela falta de segurança e limpeza, um espaço carente de atenção não atrai a população, tornando-os mais sedentários, promovendo assim obsedades, diminuição do apetite, e de energia do corpo humano, pois a falta de exercícios físicos promove sono desequilibrado, então essa total carência de espaços para conivência entre si, áreas de lazer, e espaços para atividades física projudicam sim a saúde pública (Brasil 247: Jornal digital, 2018).

A criação e implantação de parques em muitas cidades se relacionam ao conjunto de diretrizes imposto pelas Nações, afim de promover o desenvolvimento sustentável e, por isso, essas ideias merecem ser melhor debatidas. A ampliação do discurso ambiental, em especial desde os anos 1970, com a realização das grandes conferências das Nações Unidas sobre meio ambiente, culminou, entre outros, na proliferação de "espaços verdes" em muitas cidades e no aumento das desigualdades socioespaciais (Gomes et al., 2014).

Ponderam (Oliveira et al., 2006) que $12 \mathrm{~m}^{2}$ de área verde/habitante é considerado ideal, atribuido a ONU (Organização das Nações Unidas), OMS (Organização Mundial da 
Saúde), ou FAU (Faculdade de Arquitetura e Urbanismo), arraigado no Brasil, já segundo a SBAU (Sociedade Brasileira de Arborização Urbana, 1996), relata que $15 \mathrm{~m}^{2} /$ habitante seria o mínimo para áreas verdes públicas destinadas à recreação.

As áreas verdes, além de quantitativamente, deveriam ser classificadas de acordo com a faixa etária, tamanho mínimo do espaço e distância da residência, além de outros índices como cobertura vegetal, em que se consideram todas as manchas de vegetação, copas de árvores, índices de áreas verdes utilizáveis ou não, sem condições de uso, depois recalcular indicando a quantidade usada pela comunidade de acordo com suas qualificações (Oliveira et al., 2006).

A territorialidade tem sido tema recorrente nas análises sobre espaços delimitados no mundo globalizado, pela necessidade de se entender as diferenças ali inscritas, e como contraponto a uma ideologia homogeneizante, sustentada na ideia de que todas as regiões de determinados territórios são iguais no Brasil e na América Latina (Silva et al., 2016).

Aproximação entre o campo de estudos, intervenções do lazer e da Educação Física escolar, a partir de reflexões sobre uma experiência com jogos eletrônicos, da percepção da qualidade de espaços públicos de lazer e das vivências de frequentadores nesses ambientes (Vaz AF et al., 2016).

Goiânia conta com 24 parques urbanos, os quais contribuíram para que a cidade recebesse o título de capital brasileira com melhor qualidade de vida. Com base nessa ideia de qualidade de vida, os parques urbanos são colocados em evidência nos discursos oficiais e nas imagens do Marketing Turístico (Silva et al., 2013).

\section{CONSIDERAÇÕES FINAIS}

De acordo com os dados apresentados, foi possível constatar que o município de Nova Iguaçu carece de áreas que convivência e lazer, quando comparados os projetos apresentados no presente estudo. Esta constatação dá-se pelo fato de o município possuir aproximadamente 787.563 habitantes e apenas dois paques que acabam por não atrair a população por conta de má gestão e de questões segurança pública.

A disponibilidade de parques públicos fomenta a interação com o ambiente natural, além de propiciar atividades físicas com consequentes benefícios para a saúde física 
e mental.

Diante deste cenário, a integração entre a Arquitetura e Urbanismo de praças e/ ou parques torna-se fundamental para a promoção da saúde das pessoas, o que ratifica a importância desses profissionais na busta por contornar as limitações sociais que propiciem hábitos saudáveis, interação com a natureza e a sociedade.

\section{BIBLIOGRAFIA}

ALENCAR, L. S.; SOUTO, P. C.; MOREIRA, F. T. A.; SOUTO, J. S.; BORGES, C. H. A. Inventário qualiquantitativo da arborização urbana em São João do Rio do Peixe - PB. Agropecuária Científica no Semi-Árido, Patos, v. 10, n. 2, p. 117-124, 2014.

Brasil: Associação Brasileira de Normas Técnicas. NBR 9283 - Mobiliário Urbano - Classificação. Rio de Janeiro. 1986.

Brasil: Associação Brasileira de Normas Técnicas. NBR 16071 - Playgrounds. São Paulo. 2012.

Brasil 247: Jornal digital. Disponível em: <https://www.brasil247.com/pt/247/favela247/130658/Medo-faz-visitantes-evitar-o-Parque-de-Nova-Igua\%C3\%A7u.htm>. Acesso em 17 de outubro de 2018.

Catraca livre. Disponível em: <https://catracalivre.com.br/agenda/conheca-parques-que-sao-verdadeiros-oasis-no-meio-do-caos-carioca/>. Acesso em: 28 de outubro de 2018. Rio de Janeiro: UFRJ, 2009.

FREITAS, W. K..; PINHEIRO, M. A. S.; ABRAHÃO, L. L. F. Análise da Arborização de Quatro Praças no Bairro da Tijuca, RJ, Brasil. Floresta e Ambiente, v. 22, n. 1, p. 23-31, 2015.

GOMES, M. A. S. Parques urbanos, políticas públicas e sustentabilidade. Revista Mercator, Fortaleza, v. 13, n. 2, p. 79-90, mai/ago. 2014. 
GONÇALVES, S.F.; RECHIA, S. Espaços e equipamentos de lazer da Vila Nossa Senhora da Luz e suas formas de apropriação. Rev. Bras. Ciênc. Esporte [online]. 2015, vol.37, n.3, pp.265-271.

MACEDO, Silvio Soares et al. Considerações preliminares sobre o sistema de espaços livres e a constituição da esfera pública no Brasil. In: TÂNGARI, Vera Regina; ANDRADE, Rubens; SCHLEE, Mônica Bahia. Sistema de Espaços Livres: o cotidiano, apropriações e ausências. Rio

Moreira, C.A.S. Caminhos de Geografia, Uberlândia, v.14, Jun/2013.

O melhor da Baixada. Disponível em: <http://omelhordabaixada.com.br/>. Acesso em: 14 de Outubro de 2018.

OLIVEIRA, A. S.; SANCHES, L.; MUSIS, C. R.; NOGUEIRA, M. C. J. A. Benefícios da arborização em praças urbanas - o caso de Cuiabá/MT. Revista Eletrônica em Gestão, Educação e Tecnologia Ambiental, v. 9, n. 9, p. 1900-1915, 2013.

Opnião e Notícia. Disponível em: <http://opiniaoenoticia.com.br/>. Acesso em: 14 de Outubro de 2018.

PIERONE, J. M. VIZZOTTO, M. M. HELENO, M. G. V. FARHAT, C. A. V. SERAFIM A. P. Qualidade de vida de usuários de parques públicos. Boletim de psicologia vol.66 no.144 São Paulo jan. 2016.

ROMANI, N.G.; GIMENES, R.; SILVA, M.T.; PIVETTA, K.F.L.; BATISTA, G.S. Análise Quali-quantitativa da arborização na praça XV de Novembro em Ribeirão Preto - São Paulo, Brasil. Revista Árvore, Viçosa-MG, v. 36, p.479-487,2012.

SANTANA, R.L.F.; ALVES, J.A. Apropriação e Uso dos Espaços de Lazer da População Curraisnovense, Licere, Belo Horizonte, v.17, n.3, set/2014.

SANTOS, C.Z.A.; FERREIRA, R.A.; SANTOS, L.R.; SANTOS, L.I.; GOMES, S.H.; GRAÇA, D.A.S. Análise qualitativa da arborização urbana de 25 vias públicas da cidade de Aracaju SE. Ciência Florestal, v. 25, n. 3, p. 751-763, 2015. 
SILVA, E.A.P.C.S.; COSTA, P.P.S.; OLIVEIRA, L.S.; SANTOS, A.R.M.; RECHIA, S.; FREITAS, C.M.S.M. Percepção da qualidade do ambiente e vivências em espaços públicos de lazer. Revi Bras Ciênc Esporte. v.38, p. 251 - 258, Setembro, 2016.

SILVA, P.C.C.; GEREZ, A.G.; NASCIMENTO, A.C.S.; SILVA, B.O.; LOUREIRO, F.L.; ALMEIDA, F.Q.; MACHADO, G.C.; GOMES, I.M.; COSTA, J.M.; MORO, L.; ADOLFO, M.; COSTA, D.G.; RECHIA, S. XIX CONBRACE- Territorialidade e diferenças regionais no brasil e america latina: Conexões com a educação fisica e ciências do esporte. Editora Tribo, Florianópolis - SC, v. 01, 2015.

VIEIRA, STEFANELLI, A.B.; TARALLI, HADDAD, C. Design no espaço público: o mobiliário da academia da primeira idade na visão dos seus usuários”, p. 2937-2948 . In: Anais do 12을 Congresso Brasileiro de Pesquisa e Desenvolvimento em Design [= Blucher Design Proceedings, v. 9, n. 2]. São Paulo: Blucher, 2016.

ZIOBER BRASIL. Catálogo de produtos, 2015. Disponível em: <http://www.zioberbrasil. com.br/kits.php?id=2>. Acesso em: 08 jan 2015. Acesso em: 10 de out. de 2018. 